\title{
Effect of Deionization on Activated Sludge Characteristics: A Case Study of Activated Sludge Culture with Tap Water and Distilled Water
}

\author{
Pascaline Sanga, Xiuqing Kong*, Kai Zhang \\ College of Petrochemical Engineering, Lanzhou University of Technology, Lanzhou, China \\ Email: sanpassy90@gmail.com, *xqkong2@126.com, 18182526035@163.com
}

How to cite this paper: Sanga, P., Kong, X. Q., \& Zhang, K. (2019). Effect of Deionization on Activated Sludge Characteristics: A Case Study of Activated Sludge Culture with Tap Water and Distilled Water. Journal of Geoscience and Environment Protection, 7, 116-125.

https://doi.org/10.4236/gep.2019.712008

Received: November 5, 2019

Accepted: December 16, 2019

Published: December 19, 2019

Copyright $\odot 2019$ by author(s) and Scientific Research Publishing Inc. This work is licensed under the Creative Commons Attribution International License (CC BY 4.0).

http://creativecommons.org/licenses/by/4.0/

\begin{abstract}
Activated sludge dewaterability and settleability properties are of prime importance in sludge treatment and disposal. Herein, we have experimentally examined the effect of deionization on activated sludge characteristics taking a case study of activated sludge inoculated in tap water and distilled water. The quality of the effluent, both distilled water and tap water were analyzed to determine the characteristics of activated sludge. Results indicated the increasing of the sludge volume index from $51.67 \mathrm{ml} / \mathrm{g}$ to $146.9 \mathrm{ml} / \mathrm{g}$ leading to the sludge bulking for sludge inoculated in distilled water. The Capillary Suction Time (CST) of sludge cultivated in distilled water varied from 23.1 to $38.4 \mathrm{~s}$, which suggests poor dewaterability. These are due to the growth of some filamentous bacteria in distilled water system. These have further confirmed by light microscope images that showed a significant difference between the sludge systems cultivated in tap water and those grown in distilled water. The present work indeed advances our understanding of activated sludge treatment and would serve as a handy reference for researchers or scholars who want to deal with sewage water treatment.
\end{abstract}

\section{Keywords}

Activated Sludge, Sequential Batch Reactor, Sludge Volume Index, Sludge Bulking, Filamentous Bacteria

\section{Introduction}

Today, some industries including petroleum, printing and dyeing, paper, chemical, and pesticide industries discharge a large amount of wastewater which con- 
tains highly inorganic saline, recalcitrant or toxic organic pollutants, and these kinds of wastewater are of global concern for sustainable treatment ( $\mathrm{He}$ et al., 2016; Fan, Kong, \& Niu, 2014). Currently, the widely used techniques for the treatment of wastewater are adsorption method (Sales et al., 2018), membrane separation (Azile \& Nomngongo, 2018), and ion exchange or electrodialysis (Oztekin \& Altin, 2016). However, these treatment methods have been reported to have some drawbacks such as high cost, secondary pollution, and consequently, these technologies could not unfortunately applied in any conditions (Grégorio \& Lichtfouse, 2019). Unlike other techniques, the activated sludge process, which is among other biological treatment methods, is favored due to its cost-effective operation and low-risk for further contamination. Therefore, the activated sludge process is the most widely used biological treatment for pollutant removal from sewage water (Chen et al., 2018). The activated sludge is considerably the most used biological treatment to remove the many kinds of pollutants that exist in sewage water. In general, activated sludge is a diverse mixture of several particles, including colloids, organic polymers, multiple cations, and several micro-organisms. Their present amounts and contents always depend on the sources of the wastewater (Ye et al., 2016).

Within the wastewater treatment process, dewaterability and settleability properties of the sludge are always considered as the most bottleneck operation to enhance the ability of wastewater treatment plants. Microbial clusters in the sludge are one of the hindrances that affect the sludge settleability. Hence, lowing its breakage is of great value for the operation of an activated sludge wastewater treatment plant (Elnaker et al., 2018). This has led to a significant number of researches trying to improve sludge settleability and floc formation.

It has been reported that physicochemical and biological properties of activated sludge are influenced by changes in ionic strength and ionic composition of sludge (Moghadam, Soheili, \& Esfahani, 2005). Several studies have investigated the effects of various cations on sludge characteristics and found that they depend on the type of the cations, and concluded that they directly affect activated sludge properties such as floc size, shape, and density thus sludge dewaterability and settleability (Banu, 2004). Again, some studies have suggested that cations, particularly divalent cations, play a crucial role in the formation of flocs, influence floc properties such as size, density, and strength, and directly affect sludge settleability and dewaterability. The quality of the effluent from activated sludge systems is highly dependent on the efficiency of solid-liquid separation process. Separation of solid and biomass from the treated wastewater can only be achieved if effective bioflocculation occurs in the aeration tank (Murdoch, 2008). All of the above instances indicated that the ions are of significant consideration for activated sludge treatment leading to effective dewaterability and settleability. However the enhancement of these properties by the presence of ions is still not well understood. Therefore, in this work, we aim to investigate the deionization effect on the dewaterability and settleability of sewage water. A clear comparison between tap water and distilled water in terms of dewaterability and settleability 
were systematically investigated. The information provided herein would be useful to further progress in sewage water treatment.

\section{Material and Methods}

\subsection{Source of Activated Sludge}

The activated sludge used in this study was collected from the aeration tank at Qilihe sewage plant (Lanzhou city, China). The characteristics of the collected sludge samples are shown in Table 1.

\subsection{Preparation of Synthetic Wastewater}

In order to study the effect of deionization on activated sludge, the influent synthetic wastewater with a chemical oxygen demand of $640 \mathrm{mg} / \mathrm{l}$ was prepared from tap water and distilled water by dissolving glucose monohydrate $\mathrm{C}_{6} \mathrm{H}_{12} \mathrm{O}_{6} \cdot \mathrm{H}_{2} \mathrm{O}(66.96 \mathrm{~g} / \mathrm{l})$ as Carbon source, potassium phosphate monobasic $\mathrm{KH}_{2} \mathrm{PO}_{4}(1.175 \mathrm{~g} / \mathrm{l})$ as source of phosphorous and ammonium chloride $\mathrm{NH}_{4} \mathrm{Cl}$ $(4.74 \mathrm{~g} / \mathrm{l})$ as nitrogen source. The characteristics of tap and distilled water are illustrated in Table 2. All chemicals used in this paper were of the analytical grade.

\subsection{Reactor Set-Up and Operation Conditions}

All experiments were performed in two parallel sequencing batch reactors (SBR) with a working volume of 21 . The reactor one denoted SBR1 was used as the reactor with tap water, whereas the reactor two denoted SBR2 was used as the reactor with distilled water. These two reactors were fed with $200 \mathrm{ml}$ of the collected seed sludge and synthetic wastewater. The experiments in SBRs were operated at a cycle of $12 \mathrm{~h}$, and each cycle was divided into five stages (influent, aeration, sedimentation, drainage, and mud discharge), the aeration time was $11 \mathrm{~h}$, and sedimentation time was 30 minutes. As illustrated in Figure 1, a reactor was placed in an electrothermal constant temperature water bath (HH-S4, Beijing keweiyongxing instrument Co. Ltd.), a motor stirrer (JJ-1, Changhou Putian Instrument Manufacturing Co., Ltd., China) was used to mix the reactant in the reactor. Air was pumped to the reactor by the air pump through stone air diffusers in order to maintain dissolved oxygen (DO) within the range of $2-3 \mathrm{mg} / \mathrm{l}$. The temperature of the reactor was kept at $25^{\circ} \mathrm{C} \pm 1{ }^{\circ} \mathrm{C}$ and controlled by a temperature indicating controller.

\subsection{Analytical Methods}

MLSS, MLVSS, and SVI were measured in accordance with the standard methods (Federation, 1999). COD was determined by using a standard potassium dichromate method. The $\mathrm{pH}$ values were analyzed by a $\mathrm{pH}$ analyzer (pHS-3C, china). The Capillary Suction Time (CST) was measured using a capillary water absorption time tester (DP139530 Beijing Yaxinde Technology Co., Ltd, China). 
Table 1. Characteristics of collected activated sludge.

\begin{tabular}{ccc}
\hline No. & Characteristics & Parameter \\
\hline 1 & Color & Brown (Figure 3) \\
2 & $\mathrm{pH}$ & $7.05 \pm 2$ \\
3 & SVI (Sludge Volume Index) (ml/g) & 50.68 \\
4 & MLSS (Mixed Liquor Suspended Solid) $(\mathrm{mg} / \mathrm{l})$ & 2368 \\
5 & MLVSS (Mixed Liquor Volatile Suspend Solid) $(\mathrm{mg} / \mathrm{l})$ & 1700 \\
\hline
\end{tabular}

Table 2. Characteristic of tap and distilled water.

\begin{tabular}{|c|c|c|c|c|}
\hline \multirow[t]{3}{*}{ No. } & \multirow[t]{3}{*}{ Elements } & \multicolumn{2}{|c|}{ Quantity mg/l } & \multirow{3}{*}{ distilled water } \\
\hline & & tap water & & \\
\hline & & triall & trial2 & \\
\hline 1 & Calcium & 549 & 550 & 0 \\
\hline 2 & Magnesium & 19.7 & 19.6 & 0 \\
\hline 3 & Sodium & 23.4 & 23.5 & 0 \\
\hline 4 & iron & 0.01 & 0.011 & 0 \\
\hline 5 & Total Nitrogen & 1.3569 & 1.3621 & - \\
\hline 6 & Total Phosphorous & 0.0012 & 0.0011 & - \\
\hline
\end{tabular}

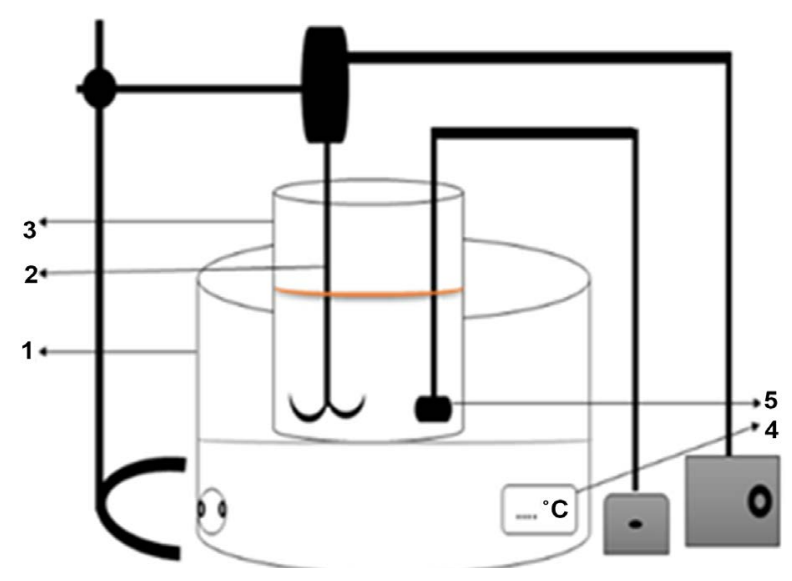

Figure 1. Experimental apparatus in an activated sludge aeration system. (1) Temperature water bath, (2) Motor stirrer, (3) Reactor, (4) Temperature indicating controller, (5) Aerator.

\section{Results and Discussions}

\subsection{Effect of Deionization on Settleability of Activated Sludge}

In this study, SVI was measured to express the sedimentation performance of SBR. SVI is defined as the sludge volume per gram of dry solid after $30 \mathrm{~min}$ of sedimentation (Wilen, 1995; Torfs et al., 2016). SVI measurement is broadly used to indicate the activated sludge settleability; thus, a lower SVI index implies 
an excellent settleability (Ye et al., 2016). We have therefore measured the SVI in both reactors in order to investigate the effect of distilled water on settleability (Figure 2). As shown in Figure 2(a), on the $6^{\text {th }}$ day, the SVI value in SBR1 was $44.42 \mathrm{ml} / \mathrm{g}$ while in SBR2, the SVI was $146.9 \mathrm{ml} / \mathrm{g}$ suggesting the activated sludge was bulking in SBR2 while in SBR1 no significant change was observed. The reason may be the same previously reported by Chen group that the activated sludge flocs were smaller and closer in the condition of high salinity and then accelerates the settlement of activated sludge (Chen et al., 2018). Furthermore, the acquired microscopic images show sludge bulking caused by the excessive growth of filamentous bacteria in SBR2 with the absence of salts, as shown in Figure 2(d). Thus, the existence of filamentous bacteria causes the poor sedimentation performance of activated sludge and deteriorate the effluent water quality. This is also evidenced in Figure 3 that the color of the activated sludge in SBR1 has no change during the experiment; in SBR2, the color changed from brown to white brown due to the development of filamentous bacteria. These findings indicate a crucial role of salts in activated sludge leading to quick sedimentation of sludge and also high settleability in SBR1.

\subsection{Effect of Deionization on Dewaterability of Activated Sludge}

The dewatering process depends on the strength of the floc structure (Abu-Orf \& Örmeci, 2005). The floc structure can vary from large compact flocs (the ideal floc), flocs with a high abundance of filamentous bacteria (filamentous bulking), or small, light flocs without filamentous bacteria (pinpoint floc). In rare cases, no or few flocs are produced with many single bacteria (dispersed growth) (Christensen, Keiding, \& Halkj, 2015). Generally, the best separation properties are obtained if the sludge contains large compact flocs, few filamentous bacteria, and a few single cells.

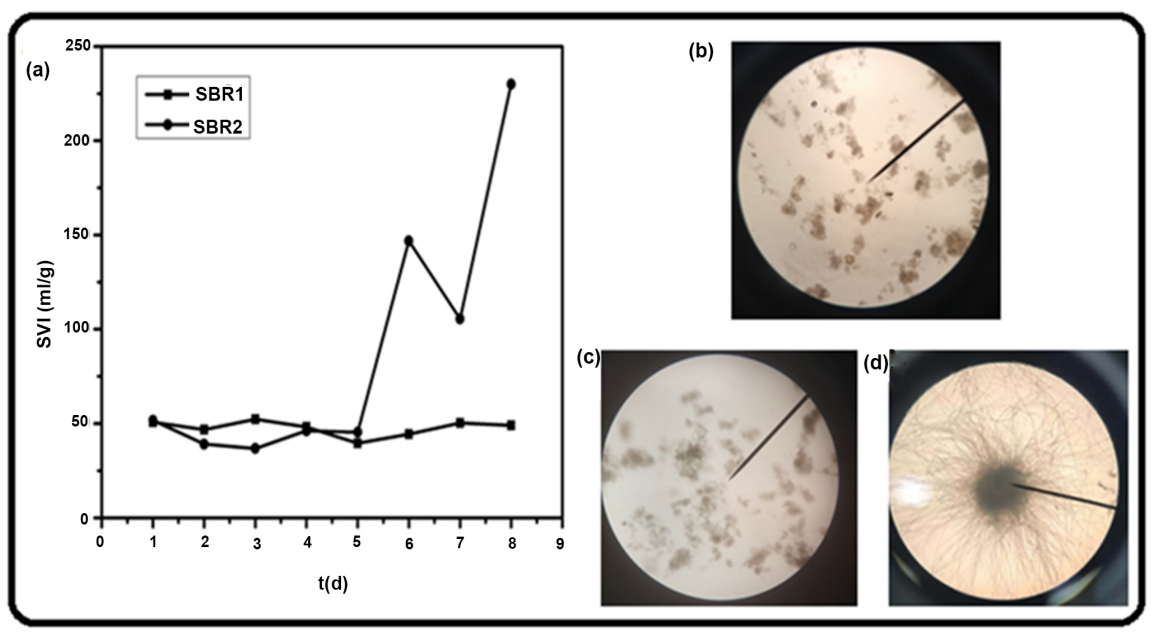

Figure 2. SVI measurement of SBR1 and SBR2 (a), microscopic images of the activated sludge at the starting of the experiment (b), SBR1 after 6 days (c), and SBR2 after 6 days (d). 


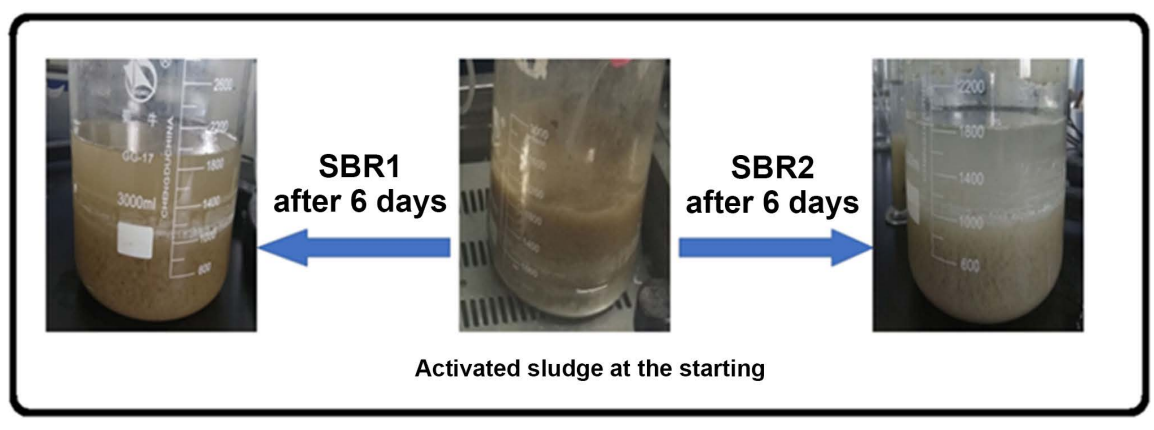

Figure 3. Change in color of sludge in two systems after 6 days. The color of the activated sludge in SBR2 changed from brown to white brown, on the other hand, in SBR1 has no change during the experiment.

CST is the time required for a set amount of filtrate out the sludge and sucked into the blotter paper by capillary force, and readings are in seconds (Sawalha, 2010). In our study, the water releasing capacity of sludge flocs, also knowns as dewaterability, was measured by CST. A good dewaterability is referred to low CST value (below 20secs), while on the contrary, a long CST is representative of a poorly dewatering sludge (Hien et al., 2007).

In this study, the sludge dewaterability gauged as CST presented an apparent difference between the two SBRs, as shown in Figure 4. The CST varied from 20.1 to $22.4 \mathrm{~s}$ within 8 days in SBR1 while it ranged from 23.1 to $38.4 \mathrm{~s}$ in SBR2. The measured CST in SBR2, suggest a poor dewaterability than of the sludge flocs in the presence of ions (SBR1). This weak dewaterability observed in SBR2 is ascribed to the presence of filamentous bacteria as discussed in the previous section. This may have happened because filamentous bacteria cause some swelling that increases the rate of sedimentation of the sludge. As a result, the moisture content of sludge increases and it is difficult to dewatering.

\subsection{Effect of Deionization on Chemical Oxygen Demand (COD) Removal Rate}

In this study, COD was obtained by calculating the amount of oxidant consumed when treating water with potassium dichromate as an oxidizing agent under strong acidity and heating, expressed in $\mathrm{mg} / \mathrm{l}$ of oxygen. The COD removal rate was used to examine system treatment performance. Figure 5(a) and Figure 5(b) show the COD and the COD removal rate in the presence and the absence of salts respectively. The absence of some salts in distilled water did not influence the COD removal rate because filamentous bacteria in SBR2 that have a stronger absorption capacity from its large surface area have no noticeable effect on COD.

\subsection{Effect of Deionization on MLSS and MLVSS of Activated Sludge}

MLSS testing measures the total concentration of mixed liquor suspended (non-soluble) solids in the aeration basin of an activated sludge system, while MLVSS refers to the concentration of Volatile Suspended Solids in sludge 


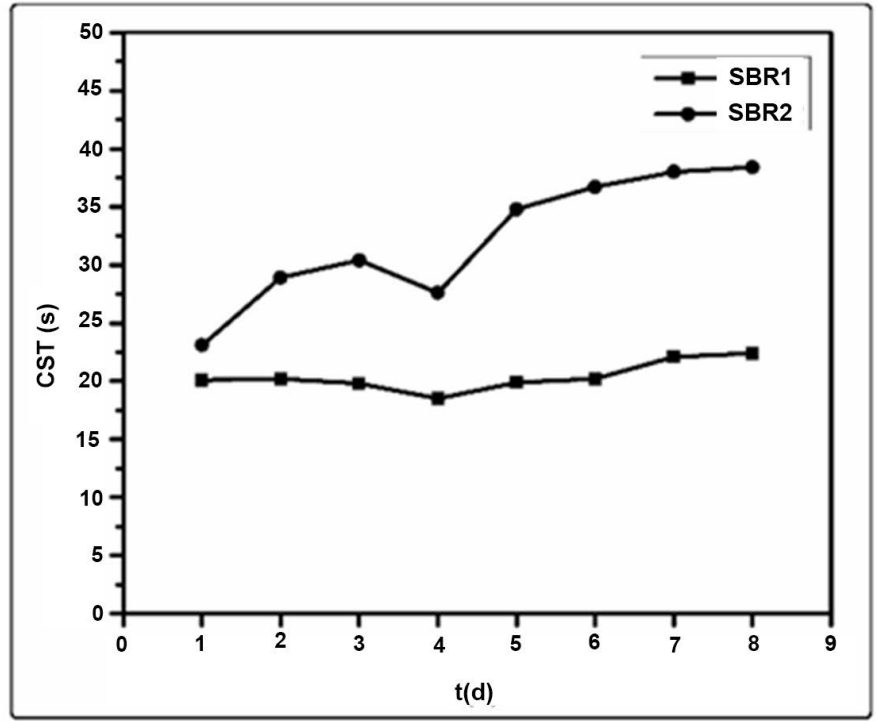

Figure 4. Capillary suction time (CST) measurement in the two reactors from day 1 to day 8 .

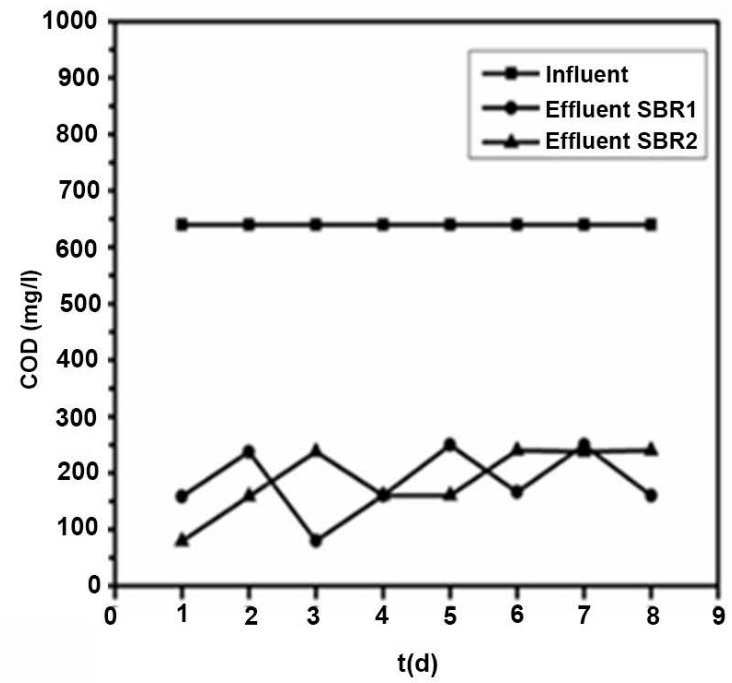

(a)

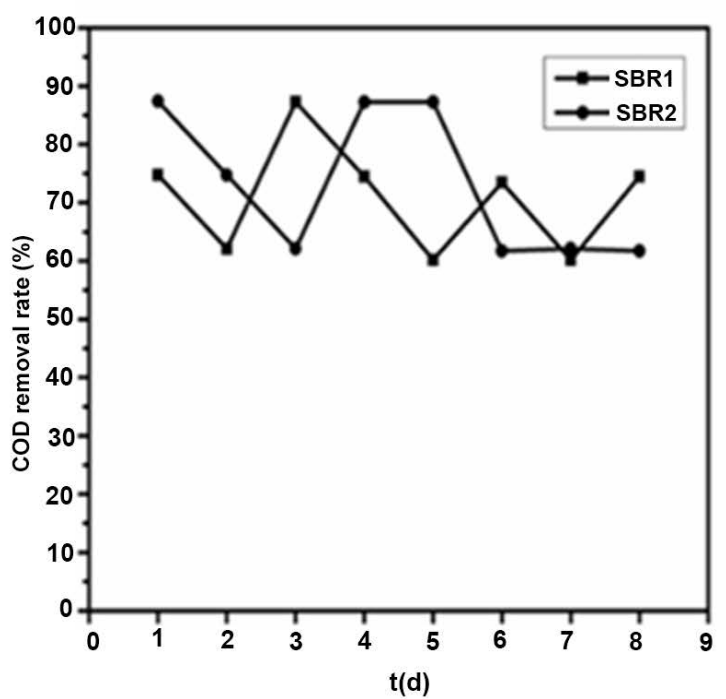

(b)

Figure 5. The variation of COD (a) and COD removal rate (b) in the two systems.

mixture, which can reflect the number of microorganisms in activated sludge, usually expressed in $\mathrm{mg} / \mathrm{l}$.

As shown in Figure 6, MLSS and MLVSS in SBR1 are more significant than in SBR2, and they increase with increasing time.

The growth rate of microorganisms is expressed as Equation (1)

$$
\mu=\frac{q_{t}-q_{0}}{t}
$$

where $\mu$ is The growth rate, $q_{0}$ is mixed liquor suspended solid or mixed liquor 

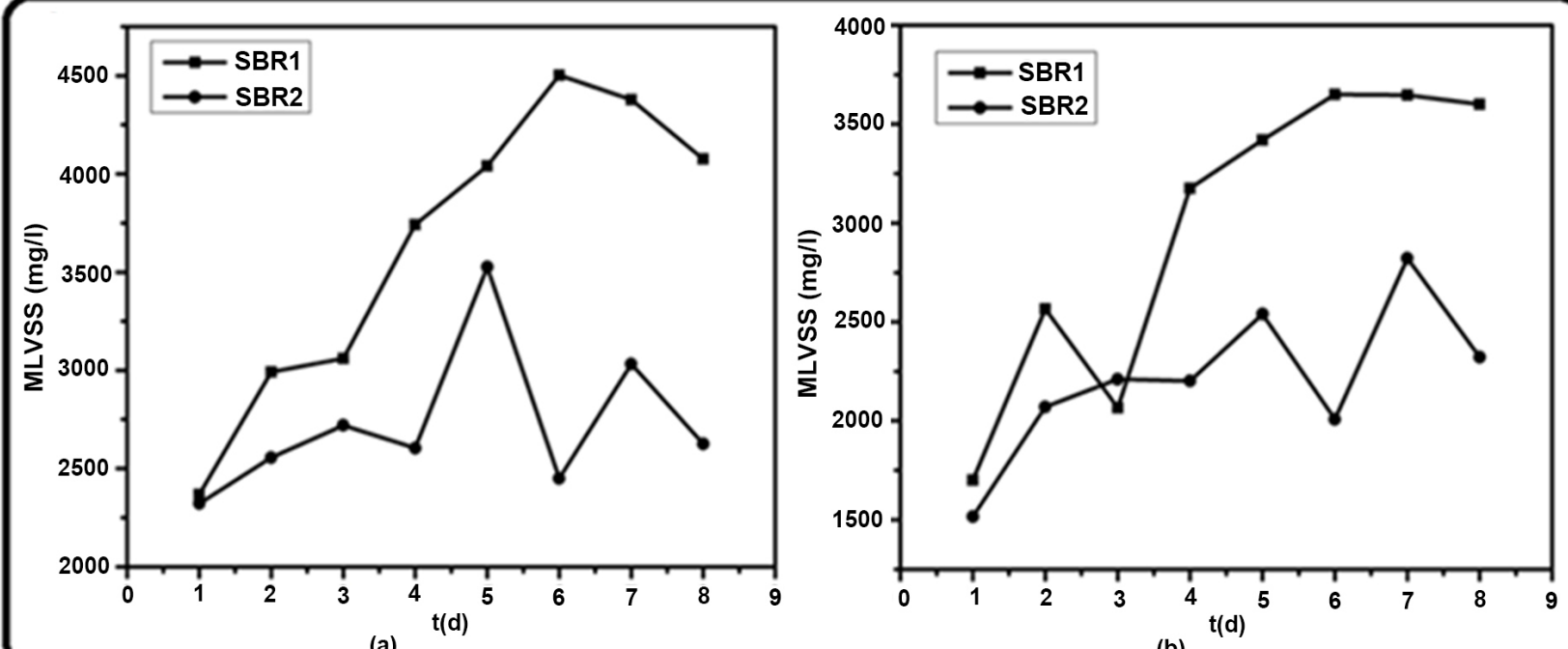

Figure 6. The variation of MLSS (a) and MLVSS (b) in the two systems.

volatile suspended solid at the starting of the experiment, $q_{t}$ is mixed liquor suspended solid or mixed liquor volatile suspended solid at the starting of bulking of the sludge and $t$ is the time required for sludge for bulking. In SBR1 the growth rate of microorganisms was $355.66 \mathrm{mg}$ MLSS/l.d and $325 \mathrm{mg}$ MLVSS/l.d while in SBR2 the growth rate of microorganisms was $21.33 \mathrm{mg}$ MLSS/l.d and 82 mg MLVSS/l.d. This indicates that the growth rate of microorganisms falls due to the growth of filamentous bacteria in SBR2.

\section{Conclusion}

To conclude, though simultaneous experiments we investigated the activated sludge properties (settleability, dewaterability) by comparing activated sludge cultivated in tap water and distilled water thus free of ions. The results indicated that the characteristic of sludge inoculated in tap water was improved in settleability and dewaterability. This is due to the hampered growth of microorganisms by ionic salts. On the other hand, the sludge inoculated in distilled water in the absence of ions has shown unimproved characteristics and ultimately resulted from the fast growth of filamentous bacteria under these conditions.

\section{Acknowledgements}

This study was financially supported by the National Natural Science Foundation of China (NSFC): "Study of sludge reduction in the biological treatment process of high calcium content wastewater" (No. 51268034).

\section{Conflicts of Interest}

The authors declare no conflicts of interest regarding the publication of this paper. 


\section{References}

Abu-Orf, M. M., \& Örmeci, B. (2005). Measuring Sludge Network Strength Using Rheology and Relation to Dewaterability, Filtration, and Thickening-Laboratory and FullScale Experiments. Journal of Environmental Engineering, 131, 1139-1147. https://doi.org/10.1061/(ASCE)0733-9372(2005)131:8(1139)

Azile Nqombolo, A. M., \& Nomngongo, R. M. M. (2018). Wastewater Treatment Using Membrane Technology. In T. Yonar (Ed.), Wastewater and Water Quality (pp. 29-40). London: IntechOpen. https://doi.org/10.5772/intechopen.76624

Banu, Ö. (2004). Freeze-Thaw Conditioning of Activated Sludge: Effect of Monovalent, Divalent, and Trivalent Cations. Journal of Residuals Science \& Technology, 1, 143-150.

Chen, Y., He, H., Liu, H., Li, H., Zeng, G., \& Xia, X. (2018). Bioresource Technology Effect of Salinity on Removal Performance and Activated Sludge Characteristics in Sequencing Batch Reactors. Bioresource Technology, 249, 890-899. https://doi.org/10.1016/j.biortech.2017.10.092

Christensen, M. L., Keiding, K., \& Halkj, P. (2015). Dewatering in Biological Wastewater Treatment: A Review. Water Research, 82, 14-24. https://doi.org/10.1016/j.watres.2015.04.019

Elnaker, N. A., Elektorowicz, M., Naddeo, V., Hasan, S. W., \& Yousef, A. F. (2018). Assessment of Microbial Community Structure and Function in Serially Passaged Wastewater Electro-Bioreactor Sludge: An Approach to Enhance Sludge Settleability. Scientific Reports, 8, Article No. 7013. https://doi.org/10.1038/s41598-018-25509-2

Fan, Y. L., Kong, X. Q., \& Niu, J. X. (2014). Influence of $\mathrm{Ca}^{2+}$ Concentration on the Nitrogen Removal in Activated Sludge Process. Journal of Petroleum Science, 30, 921-927.

Federation, W. E. (1999). Standard Methods for the Examination of Water and Wastewater Part 1000 Standard Methods for the Examination of Water and Wastewater.

Grégorio, C., \& Lichtfouse, E. (2019). Advantages and Disadvantages of Techniques Used for Wastewater Treatment. Environmental Chemistry Letters, 17, 145-155.

https://doi.org/10.1007/s10311-018-0785-9

He, H., Chen, Y., Li, X., Cheng, Y., \& Yang, C. (2016). Influence of Salinity on Microorganisms in Activated Sludge Processes: A Review. International Biodeterioration \& Biodegradation, 119, 520-527. https://doi.org/10.1016/j.ibiod.2016.10.007

Hien, V., To, P., Nguyen, T. V., Vigneswaran, S., \& Ngo, H. H. (2007). A Review on Sludge Dewatering Indices (pp. 1-23).

Moghadam, M. A., Soheili, M., \& Esfahani, M. M. (2005). Effect of Ionic Strength on Settling of Activated Sludge. Iranian Journal of Environmental Health Science \& Engineering, 2, 1-5.

Murdoch, F. K. (2008). Monovalent Cations and Their Influence on Activated Sludge Floc Chemistry, Structure, and Physical Characteristics. Biotechnology and Bioengineering, 100, 231-239. https://doi.org/10.1002/bit.21755

Oztekin, E., \& Altin, S. (2016). Wastewater Treatment by Electrodialysis System and Fouling Problems. The Online Journal of Science and Technology, 6, 91-99.

Sales, R. P., Galv, R. B., Alves, G. J., \& Almeida, P. H. (2018). Wastewater Treatment Using Adsorption Process in Column for Agricultural Purposes. Revista Ambiente \& Agua, 14, 1. https://doi.org/10.4136/1980-993X

Sawalha, O. (2010). Capillary Suction Time (CST) Test: Developments in Testing Methodology and Reliability of Results.

Torfs, E., Winkler, M. K. H., Vanrolleghem, P. A., Smets, I. Y., \& Daigger, G. T. (2016). 6 Settling Tests, 9781780404745. 
Wilen, B. (1995). Effect of Different Parameters on Settling Properties of Activated Sludge.

Ye, C., Yang, X., Zhao, F., \& Ren, L. (2016). The Shift of the Microbial Community in Activated Sludge with Calcium Treatment and Its Implication to Sludge Settle Ability. Bioresource Technology, 207, 11-18. https://doi.org/10.1016/j.biortech.2016.01.135 